\title{
Cancer Stem Cells in Lung Tumorigenesis
}

\author{
Johannes R. Kratz, MD, Adam Yagui-Beltrán, MD, and David M. Jablons, MD \\ Department of Surgery, Massachusetts General Hospital, Boston, Massachusetts; and \\ Department of Surgery, University of California San Francisco Cancer Center, San Francisco, \\ California
}

\section{Abstract}

Although stem cells were discovered more than 50 years ago, we have only recently begun to understand their potential importance in cancer biology. Recent advances in our ability to describe, isolate, and study lung stem cell populations has led to a growing recognition of the central importance cells with stem cell-like properties may have in lung tumorigenesis. This article reviews the major studies supporting the existence and importance of cancer stem cells in lung tumorigenesis. Continued research in the field of lung cancer stem cell biology is vital, as ongoing efforts promise to yield new prognostic and therapeutic targets.

\section{The Concept of Cancer Stem Cells}

In 1855 Rudolf Virchow observed that "omnis cellula e cellula" or "every cell stems from another cell" [1]. This foundational tenet of cell theory was extended to the concept of stem cells by Siminovitch and colleagues [2] in the early 1960s. They observed that colonyforming cells giving rise to spleen colonies had three characteristics that now define stem cells: self-renewal, proliferative capacity, and multipotency [3].

Several similarities between stem cells and tumor cells subsequently led to the cancer stem cell model of tumorigenesis. Like organs derived from stem cells, tumors consist of rapidly proliferating cells and also represent a heterogeneous collection of cells with different phenotypes [4]. Because these heterogeneous tumor cells are clonal in origin, they are thought to arise from a self-renewing population that gives rise to terminally differentiating progenitor cells [4]. The cells that make up the self-renewing clonal population within a tumor have been termed "cancer stem cells" because of the analogous biologic processes they undergo compared with normal stem cells [4].

The pioneering work leading to the cancer stem cell hypothesis depended on the accurate identification and isolation of tumor cells with stem cell-like properties. This was accomplished by using cell surface markers, or surface molecules, that could be used not only to identify distinct populations of unique cells by immunostaining but also to isolate these distinct populations by techniques such as flow cytometry and magnetic bead isolation [5]. Classic stem cell surface markers, as well as novel surface markers, have been used to isolate populations of tumor cells with stem cell-like properties.

In leukemia for example, only a small subset of leukemia cells are able to initiate acute myeloid leukemia in nonobese diabetes/severe combined immunodeficiency mice [6]. This

\footnotetext{
Address correspondence to Dr Kratz, Department of Surgery, UCSF Helen Diller Family Comprehensive Cancer Center, 2340 Sutter St, Rm N261, University of California-San Francisco, San Francisco, CA 94115-1724; johannes.kratz@ucsfmedctr.org.

Presented at the $2^{\text {nd }}$ International Bi-Annual Minimally Invasive Thoracic Surgery Summit, Boston, MA, October 9-10, 2009.

Drs Kratz, Yagui-Beltrán, and Jablons have no conflicts of interest to disclose.
} 
subset of leukemia cells could be identified and isolated using the stem cell surface markers cluster of differentiation (CD) 34 and CD38 [6]. Consistent with their identity as leukemia stem cells, these cells demonstrated the properties of self-renewal, proliferation, and multipotency [6].

Similar findings have been made in solid tumors in which only a small fraction of heterogeneous tumor cells are clonal. In breast cancer, for example, Al-Hajj and colleagues [7] isolated a cell population with high expression of the cell surface marker CD44 but low expression of the cell surface marker CD24. As few as $100 \mathrm{CD}_{4} 4^{+} / \mathrm{CD} 22^{-}$cells were able to form tumors in mice; these cells gave rise to mixed tumors that included not only additional CD $44^{+} / \mathrm{CD} 22^{-}$cells but also thousands of cells with alternative phenotypes [7]. Importantly, none of these alternative phenotypes were able to independently form tumors in mice [7].

CD133, a cell surface marker of neural stem cells [8], is also expressed in a small subset of cells in brain [8,9] and colon [10] tumors. Similar to the unique cell population seen in epithelial breast cancer, cancer cells expressing the cell surface molecule CD133 were observed by Singh and colleagues [8,9] and O'Brien and colleagues [10] to be the only cells capable of forming new heterogeneous tumors in mice.

The relative immunity of metastatic disease to chemotherapy might also be linked to the existence of tumor cells with stem-like properties. One of the more discouraging observations about chemotherapy is that despite its success in shrinking primary tumors, it has been largely unsuccessful in curing metastatic disease [4,5]. It has been reported that normal stem cells express high levels of antiapoptotic and drug-resistance proteins such as bcl-2, human multidrug-resistance (MDR1), and the adenosine triphosphate-binding cassette transporter, making them resistant to chemotherapy and apoptosis induction [11-13].

These observations have led some to speculate that the inability of chemotherapy to cure metastatic disease might be due to the expression of drug-resistant proteins that make stem cells inherently more resistant to toxins that kill their terminally differentiated counterparts $[4,5]$. Thus, although chemotherapy might shrink primary tumors by killing terminally differentiated cells that form the bulk of the tumor, the tumor may subsequently be repopulated by chemoresistant cancer stem cells causing tumor recurrence $[4,5]$.

Despite emerging evidence that cells within tumors with stem-cell markers and stem celllike properties exist (hereafter referred to as "cancer stem cells"), their origin still remains unclear. It is not well understood, for example, whether these cancer stem cells arise from normal stem cells that acquire oncogenic mutations or from fully differentiated cells that acquire mutations causing dedifferentiation and acquisition of stem cell-like properties [5].

Some indirect evidence supports the hypothesis that normal stem cells acquire oncogenic mutations causing malignant tumors. One group, for example, has studied Oct-4, a stem cell marker that maintains cell pluripotency in the developing embryo [14]. When overexpressed in the somatic tissues of adult mice, constitutive Oct-4 expression causes epithelial dysplasia by expansion of progenitor cells but does not affect fully differentiated cells [14]. These observations suggest that only stem cells, but not their fully differentiated counterparts, are targets of Oct-4-induced dysplasia [14].

Weaker evidence comes from the observation that continued oncogene pathway activation is necessary for epidermal tumor formation in adult transgenic mice [15]. Some interpret this observation to suggest that only clonal self-renewing cells are potential sources of malignant tumors because they alone live long enough to acquire the necessary number of mutations required for oncogenic transformation [16]. 


\section{Evidence for Lung Stem Cells in Adults}

The epithelium of the adult airways consists of three distinct compartments arranged along a proximal-distal axis (Table 1) [17]. Part of the difficulty in demonstrating the existence of adult lung stem cells has been due to the slow rate of turnover in the adult epithelium. In contrast to the rapidly proliferating cells present in the bone marrow or epidermis, the proliferative fraction has been estimated to be as small as $1.3 \%$ in the tracheal epithelium and $0.06 \%$ in bronchiolar epithelium [17]. Despite these difficulties, evidence now exists supporting the presence adult stem cells in each of the epithelial compartments.

The proximal airways, composed of the trachea and main bronchi, are lined by pseudostratified epithelium [17]. Keratin (K)-expressing basal cells have been shown to have capacities for self-renewal, proliferation, and multipotency, making them putative major airway stem cells $[18,19,21,22]$. Borthwick and colleagues [21] used an epithelial injury mouse model to demonstrate the presence of tracheal K5-expressing basal stem cells. Mouse airways were injured by intratracheal detergent or sulfur dioxide inhalation, and the proliferation and localization of bromodeoxyuridine label-retaining cells was observed in the trachea during and after injury. These label-retaining cells were found in the same niches as cells with high $K 5$ promoter activity [21]. Transgenic mice expressing $K 5$-promoter-driven enhanced green fluorescent protein demonstrated enhanced green fluorescent protein expression in these putative stem cell niches, confirming $\mathrm{K} 5$ expression in these selfrenewing tracheal stem cells [22]. K5-expressing cells also demonstrated a 4.5-fold greater capacity to form colonies and a 12-fold greater capacity to form large colonies in vitro, demonstrating the proliferative potential of these self-renewing tracheal stem cells [22].

Rawlins and colleagues [23] confirmed these observations by using elegant lineage tracing experiments that support the pluripotency of tracheal K5-expressing basal cells. Hong and colleagues $[18,19]$ used a naphthalene airway injury mouse model to demonstrate the multipotency of tracheal keratin-expressing basal cells $[18,19]$. In their model, injury resulted in the rapid induction of K14-expressing basal cells. Transgenic mice harboring a K14 promoter linked to a lox-cre reporter were used to show that these rapidly proliferating K14-expressing basal cells gave rise to phenotypically heterogenous progeny, including clonal species of the original K14-expressing basal cells, demonstrating self-renewal, proliferation, and multipotency of these tracheal stem cells $[18,19]$.

The bronchioles of middle airways are lined by simplified columnar epithelium [17]. Two types of bronchiolar progenitor cells that proliferate in response to injury have been described. Rapidly proliferating bronchiolar progenitor cells were first reported in classic studies by Evans and colleagues [31,32] in a rat model of nitrogen oxide/ozone inhalation injury. They demonstrated that mature Clara cells could transiently dedifferentiate and give rise to phenotypically different bronchiolar epithelial cells after inhalation injury [31,32]. These Clara cells are functionally equivalent to mature differentiated epithelial cells in the quiescent steady state but have the potential to become transit-amplifying cells (Clara type A cells) that give rise to diverse progeny in response to injury [29,33]. Although originally described as "lung stem cells," these Clara cells have recently been redesignated as "facultative progenitor cells" [29,33].

More recent studies have identified other populations of bronchiolar progenitor cells resistant to naphthalene-induced injury that likely represent true bronchial airway stem cells [34]. Because Clara cells are selectively damaged by naphthalene [35], these models allow for the study of progenitor cells in a Clara-cell depleted environment. These models have shown that neuroepithelial bodies contain two separate populations of cells that proliferate in response to naphthalene-induced injury [24]. The first population consists of calcitonin 
gene-related peptide-positive pulmonary neuroendocrine cells that proliferate and form hyperplastic lesions after naphthalene injury [25]. The second population consists of Claracell secretory protein (CCSP)-positive cells that proliferate and repopulate bronchiole airways with phenotypically diverse progeny after naphthalene exposure [24-26]. The inability of calcitonin gene-related peptide-positive pulmonary neuroendocrine cells to independently repopulate naphthalene-injured airways implies that neuroepithelial bodies $\mathrm{CCSP}^{+}$cells represent true bronchial airway stem cells [26] (Table 1).

The distal airways are composed of respiratory bronchioles and alveoli that are lined by cuboidal epithelium [17]. The bronchioalveolar duct junction (BADJ) has been identified in recent studies as a microenvironment harboring airway stem cells. In 2002 Giangreco and colleagues [36] identified a neuroepithelial bodies-independent CCSP-expressing population in the BADJ that was capable of proliferation and self-renewal after naphthalene-induced injury. These $\mathrm{CCSP}^{+} \mathrm{BADJ}$ cells gave rise to populations of label-retaining cells with different mitotic rates, suggestive of multipotent potential [36]. In $2005 \mathrm{Kim}$ and colleagues [38] reported that these CCSP ${ }^{+}$BADJ cells coexpressed surfactant protein C (SP-C). Further characterization demonstrated that these cells displayed a Sca- $1^{+} / \mathrm{CD} 45^{-} /$platelet-endothelial cell adhesion molecule (PECAM) ${ }^{-} / \mathrm{CD} 34^{+}$cell-surface marker phenotype [28]. This Sca $-1^{+} / \mathrm{CD} 45^{-} / \mathrm{PECAM}^{-} / \mathrm{CD} 34^{+}$population was capable of proliferation, self-renewal, and multilineage differentiation in culture, suggesting they represented true distal airway stem cells [28].

Recently, several groups have challenged these observations. Teisanu and colleagues [29] suggested that $\mathrm{CD} 45^{-} / \mathrm{CD} 31^{-} / \mathrm{CD} 34^{-} / \mathrm{Sca}-1^{\text {low }} / \mathrm{AF}^{\text {low }}$ is a more appropriate defining phenotype of BADJ stem cells. Through lineage tracing experiments, Rawlins and colleagues [23] demonstrated that Clara cells are not able to give rise to type II alveolar cells and suggest instead that Id $2^{+}$is an appropriate marker of lung distal tip epithelial stem cells [30]. Research to characterize true cell marker phenotypes of distal airway stem cells is ongoing [30].

\section{Evidence for Lung Cancer Stem Cells}

Different types of human lung cancer tend to localize along the same proximal-to-distal axis as airway epithelium [37] (Table 1). Preliminary evidence points to the existence of cancer stem cells in each of these lung cancer types (extensively reviewed by Giangreco and colleagues [37]). Squamous cell carcinomas, for example, tend to be centrally located tumors [37]. Barth and colleagues [20] observed that squamous cell metaplasia was enriched in basal cells expressing K5, suggesting that the proliferating basal cells seen in squamous cell metaplasia are tracheal basal stem cells. Small cell lung carcinomas (SCLC), on the other hand, predominantly occur in the midlevel bronchioles [37]. Gutova and colleagues [27] demonstrated the existence of populations of cells that exhibited multidrug resistance, clonogenic proliferation, and the expression of the putative stem cell markers CD44 and MDR1 using the marker urokinase plasminogen activator receptor in six SCLC cell lines [27]. Lastly, human adenocarcinomas and bronchioalveolar carcinomas, commonly recognized as a subtype of adenocarcinomas, tend to occur in the distal airways [37]. Kim and colleagues [28] demonstrated that BADJ stem cells are expanded in their mouse model of adenocarcinoma after K-ras activation in a dose-dependent manner (discussed more extensively below).

Recent studies provide additional evidence supporting the existence of lung cancer stem cells. Ho and colleagues [38] isolated populations of cells that efflux Hoechst 33342 dye from six human lung cancer cell lines. These cells exhibited several properties typical of stem cells, including clonogenic proliferation, invasive phenotypes in 3D Matrigel (BD 
Biosciences, San Jose, CA) culture, multi-drug resistance, and increased telomerase expression [38]. Hoechst 33342-staining cells were also found in small amounts in 16 human lung cancer specimens [38].

Eramo and colleagues [39] demonstrated a population of $\mathrm{CD} 133^{+}$cells with stem cell properties in human lung cancers and in naphthalene-induced injury mouse models. Specimens of human non-small cell lung cancer (NSCLC) and SCLC demonstrated enrichment of $\mathrm{CD}_{133^{+}}$cells in these tumors compared with controls with healthy lungs, a finding mirrored in naphthalene-injured murine airways compared with uninjured airways [39]. CD133 ${ }^{+}$cells isolated from freshly resected human lung cancer specimens could be grown indefinitely in culture and generated tumors similar in phenotypic diversity to the original tumor when injected into immunodeficient mice [39]. Bertolini and colleagues [40] independently reported similar findings using $\mathrm{CD} 133^{+}$cells isolated from 60 human lung cancer samples.

A third group reported that the proliferative potential, invasiveness, and chemoresistance of $\mathrm{CD} 133^{+}$cells isolated from human lung tumors was dependent on Oct- 4 expression, consistent with the known importance of Oct-4 in embryonic stem cell development [41,42]. Together, these data support the notion that these self-renewing, multipotent $\mathrm{CD} 133^{+}$cells are lung cancer stem cells.

Several classic tumorigenic pathways and developmental pathways have been implicated in lung cancer stem cell development. Among the classic oncogenic pathways, one of the most important and well studied is the K-ras pathway. Activation of the K-ras pathway leads to the development of lung adenocarcinomas in humans and in mouse models [43]. In 2001 Jackson and colleagues [44] reported findings implicating the K-ras pathway in the development of lung cancer stem cells. Using a transgenic mouse with inducible $K$-ras activation in lung tissues, they observed that a small number of cells within hyperplastic lesions and in adenomas expressed CCSP as well as the type II alveolar cell marker SP-C [44]. They hypothesized that these cells expressing $\mathrm{CCSP}^{+} \mathrm{SP}_{-} \mathrm{C}^{+}$represented transdifferentiating Clara cells or K-ras activation in lung cancer stem cells that had the potential to develop into both Clara and type II cells [44]. In 2005 they confirmed the latter hypothesis by demonstrating that K-ras pathway activation led to BADJ stem cell expansion in a dose-dependent fashion in vivo and in vitro [28]. Exposing these mice to naphthalene, known to stimulate BADJ stem cell expansion, increased lung tumor surface area by an average of 11-fold [28].

This group recently reported that Bmil, a known oncogene, is necessary for K-ras-induced tumorigenesis in their mouse model [45]. Loss of Bmil in their K-ras transgenic mice decreased the prevalence and progression of lung tumors and impaired BADJ stem cell proliferation and self-renewal in vivo and in vitro [45].

In addition to the K-ras oncogenic pathway, developmental signaling pathways known to regulate normal stem cell self-renewal and proliferation have also been linked to the development of lung cancer. The phosphoinositide 3-kinases (PI3K)/phosphatase and tensin homolog (PTEN)/protein kinase B (Akt) pathway, for example, is known to be necessary for normal stem cell function [46]. Several groups have also observed that this key stem cell pathway has a tumor-suppressor function in a variety of cancers, including NSCLC [47]. Loss of PTEN expression, for example, has been reported to result in constitutively active PI3K signaling in NSCLC [48].

Recent work has linked the PI3K/PTEN/Akt pathway to lung cancer stem cells and to suppression of $K$-ras mutations [48-50]. Spontaneous lung adenocarcinomas develop in transgenic mice with inducible loss of PTEN expression in bronchioalveolar cells [50]. 
Before the development of these adenocarcinomas, there is an expansion of $\mathrm{Sca}-1^{+} / \mathrm{CD} 45^{-} /$ $\mathrm{PECAM}^{-} / \mathrm{CD} 34^{+} \mathrm{BADJ}$ stem cells and population cells that exhibit Hoechst dye efflux properties [50]. Interestingly, loss of PTEN expression results in $K$-ras mutations in $33 \%$ of mice developing spontaneous adenocarcinomas [50]. In addition, loss of PTEN expression in $K$-ras mutant mice results in more advanced and extensive adenocarcinomas than in $K$-ras mutant mice alone [49]. Consistent with these observations, inhibitors of PI3K signaling block expansion of Sca- $1^{+} / \mathrm{CD} 45^{-} / \mathrm{PECAM}^{-} / \mathrm{CD} 34^{+} \mathrm{BADJ}$ stem cells and also tumor growth $[48,51]$. Together, these data suggest that loss of PTEN expression and PI3K activation leads to increased BADJ stem and side-population cells and increases the frequency of $K$-ras mutations, resulting in the subsequent development of lung adenocarcinoma.

In addition to the PI3K/PTEN/Akt pathway, two pathways recognized to be important during embryonic lung development have also been linked to lung cancer stem cells [52]. The Hedgehog $(\mathrm{Hh})$ signaling pathway acts as an important regulator of stem cell fates during embryonic development and has been linked to SCLC [53,54]. The observation that intraepithelial Hh signaling is increased after naphthalene-induced airway injury suggests that progenitor cells activate $\mathrm{Hh}$ signaling in response to injury [53,54]. Increased $\mathrm{Hh}$ signaling is also observed in the lungs of PTEN-deficient mice that develop spontaneous lung adenocarcinomas in conjunction with BADJ stem cell expansion, implying a causal role for Hh signaling in this process [50]. The Wnt developmental pathway is another critical regulator of embryonic lung stem cells [55,56]. In adult mice, conditional deletion of p38 a, a known downstream target of noncanonical Wnt signaling [57], leads to an expansion of $\mathrm{CCSP}^{+} \mathrm{SP}_{-} \mathrm{C}^{+}$stem cells, hyperproliferation, and increased sensitization to K-ras-induced tumorigenesis [58]. These recent observations suggest it is likely that we will continue to discover the importance of reactivation of these nascent embryonic stem cell pathways in lung tumorigenesis.

\section{Summary and Future Directions}

Although the concept of human stem cells was first formulated more than 50 years ago, the notion that cells with stem-like properties may have an important causal influence in cancer, and in lung cancer in particular, represents a recent advancement in our overall understanding of tumorigenesis. The studies we have reviewed lay a convincing groundwork for our ongoing understanding of the casual role of cancer stem cells in tumorigenesis; however, many questions remain unanswered. Chief among these is the influence of the microenvironment on the transformation and progression of lung cancer stem cells. Many of the studies have demonstrated stem cell-like behavior of putative stem cell populations by xenograft transplantation models or in vitro cell culture. This ignores the possibility that development of stem cell niche autonomy due to microenvironment factors and inflammatory cells/mediators may have an active role in lung cancer pathogenesis [59-62].

The importance of continued research in this area is underscored by preliminary evidence demonstrating that the acquisition of "stemness" by NSCLC tumors is a negative prognostic and predictive factor in overall survival. Loss of PTEN expression, for example, has important ramifications in lung cancer stem cells, as detailed above, and is also an independent prognostic factor in overall survival of patients with NSCLC [63]. Similarly, stage IIIB/IV NSCLC patients with tumors enriched in CD133 ${ }^{+}$lung cancer stem cells tend to have shorter progression-free survival after treatment with platinum-based chemotherapy [40].

A better understanding of lung cancer stem cell biology promises to lead to new approaches to treatment, especially of advanced disease. One of the paradigm shifts that may occur is a 
change in our concept of metastatic tumor cells. One group has already demonstrated that most early metastatic breast cancer cells have a stem cell phenotype [64]. The acquisition of stem cell features may explain why early metastatic disease escapes immunosurveillance: these metastatic cells are disguised from the immune system by being phenotypically similar to native stem cells. These observations, combined with the previously referenced work demonstrating that stem cells are resistant to chemotherapeutics due to the antiapoptosis and drug-resistant genes they express, may mean that finding effective therapy for advancedstage lung cancer will ultimately require isolating and specifically targeting lung cancer stem cells. Although the traditional approach of demonstrating therapeutic effectiveness by reduced tumor burden is widely accepted, it may prove meaningless if what is really important is reducing the cancer stem cell burden. In the future, the effectiveness of therapeutics for both early and advanced disease may indeed be measured in terms of their potency against lung cancer stem cell populations.

It is not unreasonable to speculate that the next major breakthrough in antitumor therapeutics will target one of the oncogenic, tumor suppressor, or developmental pathways that confer "stemness" to lung tumors. Ongoing research efforts in the field of lung cancer stem cell biology are therefore vital, as forthcoming advances in the fight against lung cancer lie on the stem cell horizon.

\section{Acknowledgments}

This work was supported by the Wyeth Scholarship of the American College of Surgeons, The Kazan Foundation, and the NIH/NCI R011R01CA093708-01A3 grant.

\section{References}

1. Mazzarello P. A unifying concept: the history of cell theory. Nat Cell Biol 1999;1:13-5.

2. Siminovitch L, McCulloch EA, Till JE. The distribution of colony-forming cells among spleen colonies. J Cell Physiol 1963;62:327-36. [PubMed: 14086156]

3. McCulloch EA, Till JE. Perspectives on the properties of stem cells. Nat Med 2005;11:1026-8. [PubMed: 16211027]

4. Reya T, Morrison SJ, Clarke MF, Weissman IL. Stem cells, cancer, and cancer stem cells. Nature 2001;414:105-11. [PubMed: 11689955]

5. Pardal R, Clarke MF, Morrison SJ. Applying the principles of stem-cell biology to cancer. Nat Rev Cancer 2003;3:895-902. [PubMed: 14737120]

6. Bonnet D, Dick JE. Human acute myeloid leukemia is organized as a hierarchy that originates from a primitive hematopoietic cell. Nat Med 1997;3:730-7. [PubMed: 9212098]

7. Al-Hajj M, Wicha MS, Benito-Hernandez A, Morrison SJ, Clarke MF. Prospective identification of tumorigenic breast cancer cells. Proc Natl Acad Sci U S A 2003;100:3983-8. [PubMed: 12629218]

8. Singh SK, Clarke ID, Terasaki M, et al. Identification of a cancer stem cell in human brain tumors. Cancer Res 2003;63:5821-8. [PubMed: 14522905]

9. Singh SK, Hawkins C, Clarke ID, et al. Identification of human brain tumour initiating cells. Nature 2004;432:396-401. [PubMed: 15549107]

10. O'Brien CA, Pollett A, Gallinger S, Dick JE. A human colon cancer cell capable of initiating tumour growth in immuno-deficient mice. Nature 2007;445:106-10. [PubMed: 17122772]

11. Zhou S, Schuetz JD, Bunting KD, et al. The ABC transporter Bcrp1/ABCG2 is expressed in a wide variety of stem cells and is a molecular determinant of the side-population phenotype. Nat Med 2001;7:1028-34. [PubMed: 11533706]

12. Domen J, Gandy KL, Weissman IL. Systemic overexpression of BCL-2 in the hematopoietic system protects transgenic mice from the consequences of lethal irradiation. Blood 1998;91:227282. [PubMed: 9516125]

13. Chaudhary PM, Roninson IB. Expression and activity of P-glycoprotein, a multidrug efflux pump, in human hematopoietic stem cells. Cell 1991;66:85-94. [PubMed: 1712673] 
14. Hochedlinger K, Yamada Y, Beard C, Jaenisch R. Ectopic expression of Oct-4 blocks progenitorcell differentiation and causes dysplasia in epithelial tissues. Cell 2005;121:465-77. [PubMed: 15882627]

15. Lo Celso C, Prowse DM, Watt FM. Transient activation of beta-catenin signalling in adult mouse epidermis is sufficient to induce new hair follicles but continuous activation is required to maintain hair follicle tumours. Development 2004;131:1787-99. [PubMed: 15084463]

16. Owens DM, Watt FM. Contribution of stem cells and differentiated cells to epidermal tumours. Nat Rev Cancer 2003;3:444-51. [PubMed: 12778134]

17. Snyder JC, Teisanu RM, Stripp BR. Endogenous lung stem cells and contribution to disease. J Pathol 2009;217:254-64. [PubMed: 19039828]

18. Hong KU, Reynolds SD, Watkins S, Fuchs E, Stripp BR. Basal cells are a multipotent progenitor capable of renewing the bronchial epithelium. Am J Pathol 2004;164:577-88. [PubMed: 14742263]

19. Hong KU, Reynolds SD, Watkins S, Fuchs E, Stripp BR. In vivo differentiation potential of tracheal basal cells: evidence for multipotent and unipotent subpopulations. Am J Physiol Lung Cell Mol Physiol 2004;286:L643-9. [PubMed: 12871857]

20. Barth PJ, Koch S, Muller B, Unterstab F, von Wichert P, Moll R. Proliferation and number of Clara cell 10-kDa protein (CC10)-reactive epithelial cells and basal cells in normal, hyperplastic and metaplastic bronchial mucosa. Virchows Arch 2000;437:648-55. [PubMed: 11193477]

21. Borthwick DW, Shahbazian M, Krantz QT, Dorin JR, Randell SH. Evidence for stem-cell niches in the tracheal epithelium. Am J Respir Cell Mol Biol 2001;24:662-70. [PubMed: 11415930]

22. Schoch KG, Lori A, Burns KA, Eldred T, Olsen JC, Randell SH. A subset of mouse tracheal epithelial basal cells generates large colonies in vitro. Am J Physiol Lung Cell Mol Physiol 2004;286:L631-42. [PubMed: 12959927]

23. Rawlins EL, Okubo T, Que J, et al. Epithelial stem/progenitor cells in lung postnatal growth, maintenance, and repair. Cold Spring Harb Symp Quant Biol 2008;73:291-5. [PubMed: 19028985]

24. Reynolds SD, Giangreco A, Power JH, Stripp BR. Neuroepithelial bodies of pulmonary airways serve as a reservoir of progenitor cells capable of epithelial regeneration. Am J Pathol 2000;156:269-78. [PubMed: 10623675]

25. Reynolds SD, Hong KU, Giangreco A, et al. Conditional Clara cell ablation reveals a selfrenewing progenitor function of pulmonary neuroendocrine cells. Am J Physiol Lung Cell Mol Physiol 2000;278:L1256-63. [PubMed: 10835332]

26. Hong KU, Reynolds SD, Giangreco A, Hurley CM, Stripp BR. Clara cell secretory proteinexpressing cells of the airway neuroepithelial body microenvironment include a label-retaining subset and are critical for epithelial renewal after progenitor cell depletion. Am J Respir Cell Mol Biol 2001;24:671-81. [PubMed: 11415931]

27. Gutova M, Najbauer J, Gevorgyan A, et al. Identification of uPAR-positive chemoresistant cells in small cell lung cancer. PLoS One 2007;2:e243. [PubMed: 17327908]

28. Kim CF, Jackson EL, Woolfenden AE, et al. Identification of bronchioalveolar stem cells in normal lung and lung cancer. Cell 2005;121:823-35. [PubMed: 15960971]

29. Teisanu RM, Lagasse E, Whitesides JF, Stripp BR. Prospective isolation of bronchiolar stem cells based upon immuno-phenotypic and autofluorescence characteristics. Stem Cells 2009;27:612-22. [PubMed: 19056905]

30. Rawlins EL, Clark CP, Xue Y, Hogan BL. The Id2+ distal tip lung epithelium contains individual multipotent embryonic progenitor cells. Development 2009;136:3741-5. [PubMed: 19855016]

31. Evans MJ, Cabral-Anderson LJ, Freeman G. Role of the Clara cell in renewal of the bronchiolar epithelium. Lab Invest 1978;38:648-53. [PubMed: 661220]

32. Evans MJ, Johnson LV, Stephens RJ, Freeman G. Renewal of the terminal bronchiolar epithelium in the rat following exposure to NO2 or O3. Lab Invest 1976;35:246-57. [PubMed: 957607]

33. Stripp BR. Hierarchical organization of lung progenitor cells: is there an adult lung tissue stem cell? Proc Am Thorac Soc 2008;5:695-8. [PubMed: 18684719]

34. Stripp BR, Maxson K, Mera R, Singh G. Plasticity of airway cell proliferation and gene expression after acute naphthalene injury. Am J Physiol 1995;269:791-9. 
35. Mahvi D, Bank H, Harley R. Morphology of a naphthalene-induced bronchiolar lesion. Am J Pathol 1977;86:558-72. [PubMed: 842612]

36. Giangreco A, Reynolds SD, Stripp BR. Terminal bronchioles harbor a unique airway stem cell population that localizes to the bronchoalveolar duct junction. Am J Pathol 2002;161:173-82. [PubMed: 12107102]

37. Giangreco A, Groot KR, Janes SM. Lung cancer and lung stem cells: strange bedfellows? Am J Respir Crit Care Med 2007;175:547-53. [PubMed: 17158280]

38. Ho MM, Ng AV, Lam S, Hung JY. Side population in human lung cancer cell lines and tumors is enriched with stem-like cancer cells. Cancer Res 2007;67:4827-33. [PubMed: 17510412]

39. Eramo A, Lotti F, Sette G, et al. Identification and expansion of the tumorigenic lung cancer stem cell population. Cell Death Differ 2008;15:504-14. [PubMed: 18049477]

40. Bertolini G, Roz L, Perego P, et al. Highly tumorigenic lung cancer CD133+ cells display stemlike features and are spared by cisplatin treatment. Proc Natl Acad Sci U S A 2009;106:16281-6. [PubMed: 19805294]

41. Boiani M, Scholer HR. Regulatory networks in embryo-derived pluripotent stem cells. Nat Rev Mol Cell Biol 2005;6:872-84. [PubMed: 16227977]

42. Nichols J, Zevnik B, Anastassiadis K, et al. Formation of pluripotent stem cells in the mammalian embryo depends on the POU transcription factor Oct4. Cell 1998;95:379-91. [PubMed: 9814708]

43. Malkinson AM. Molecular comparison of human and mouse pulmonary adenocarcinomas. Exp Lung Res 1998;24:541-55. [PubMed: 9659582]

44. Jackson EL, Willis N, Mercer K, et al. Analysis of lung tumor initiation and progression using conditional expression of oncogenic K-ras. Genes Dev 2001;15:3243-8. [PubMed: 11751630]

45. Dovey JS, Zacharek SJ, Kim CF, Lees JA. Bmi1 is critical for lung tumorigenesis and bronchioalveolar stem cell expansion. Proc Natl Acad Sci U S A 2008;105:11857-62. [PubMed: 18697930]

46. Hill R, Wu H. PTEN, stem cells, and cancer stem cells. J Biol Chem 2009;284:11755-9. [PubMed: 19117948]

47. Marsit CJ, Zheng S, Aldape K, et al. PTEN expression in non-small-cell lung cancer: evaluating its relation to tumor characteristics, allelic loss, and epigenetic alteration. Hum Pathol 2005;36:76876. [PubMed: 16084946]

48. Yang Y, Iwanaga K, Raso MG, et al. Phosphatidylinositol 3-kinase mediates bronchioalveolar stem cell expansion in mouse models of oncogenic K-ras-induced lung cancer. PLoS One 2008;3:e2220. [PubMed: 18493606]

49. Iwanaga K, Yang Y, Raso MG, et al. Pten inactivation accelerates oncogenic K-ras-initiated tumorigenesis in a mouse model of lung cancer. Cancer Res 2008;68:1119-27. [PubMed: 18281487]

50. Yanagi S, Kishimoto H, Kawahara K, et al. Pten controls lung morphogenesis, bronchioalveolar stem cells, and onset of lung adenocarcinomas in mice. J Clin Invest 2007;117:2929-40. [PubMed: 17909629]

51. Ihle NT, Williams R, Chow S, et al. Molecular pharmacology and antitumor activity of PX-866, a novel inhibitor of phosphoinositide-3-kinase signaling. Mol Cancer Ther 2004;3:763-72. [PubMed: 15252137]

52. Yagui-Beltran A, He B, Jablons DM. The role of cancer stem cells in neoplasia of the lung: past, present and future. Clin Transl Oncol 2008;10:719-25. [PubMed: 19015068]

53. Watkins DN, Berman DM, Baylin SB. Hedgehog signaling: progenitor phenotype in small-cell lung cancer. Cell Cycle 2003;2:196-8. [PubMed: 12734424]

54. Watkins DN, Berman DM, Burkholder SG, Wang B, Beachy PA, Baylin SB. Hedgehog signalling within airway epithelial progenitors and in small-cell lung cancer. Nature 2003;422:313-7. [PubMed: 12629553]

55. Reynolds SD, Zemke AC, Giangreco A, et al. Conditional stabilization of beta-catenin expands the pool of lung stem cells. Stem Cells 2008;26:1337-46. [PubMed: 18356571]

56. Zhang Y, Goss AM, Cohen ED, et al. A Gata6-Wnt pathway required for epithelial stem cell development and airway regeneration. Nat Genet 2008;40:862-70. [PubMed: 18536717] 
57. Ma L, Wang HY. Mitogen-activated protein kinase p38 regulates the Wnt/cyclic GMP/Ca2+ noncanonical pathway. J Biol Chem 2007;282:28980-90. [PubMed: 17684012]

58. Ventura JJ, Tenbaum S, Perdiguero E, et al. p38alpha MAP kinase is essential in lung stem and progenitor cell proliferation and differentiation. Nat Genet 2007;39:750-8. [PubMed: 17468755]

59. Coussens LM, Werb Z. Inflammation and cancer. Nature 2002;420:860-7. [PubMed: 12490959]

60. Mantovani A, Allavena P, Sica A, Balkwill F. Cancer-related inflammation. Nature 2008;454:43644. [PubMed: 18650914]

61. Marx J. Cancer biology. All in the stroma: cancer's Cosa Nostra. Science 2008;320:38-41. [PubMed: 18388269]

62. Yagui-Beltraìn, A.; He, B.; Jablons, DM. Stem Cells and lung cancer. In: Majumder, S., editor. Stem cells and cancer. 1. New York, NY: Springer; 2009. p. 193-222.

63. Tang JM, He QY, Guo RX, Chang XJ. Phosphorylated Akt overexpression and loss of PTEN expression in non-small cell lung cancer confers poor prognosis. Lung Cancer 2006;51:181-91. [PubMed: 16324768]

64. Balic M, Lin H, Young L, et al. Most early disseminated cancer cells detected in bone marrow of breast cancer patients have a putative breast cancer stem cell phenotype. Clin Cancer Res 2006;12:5615-21. [PubMed: 17020963] 


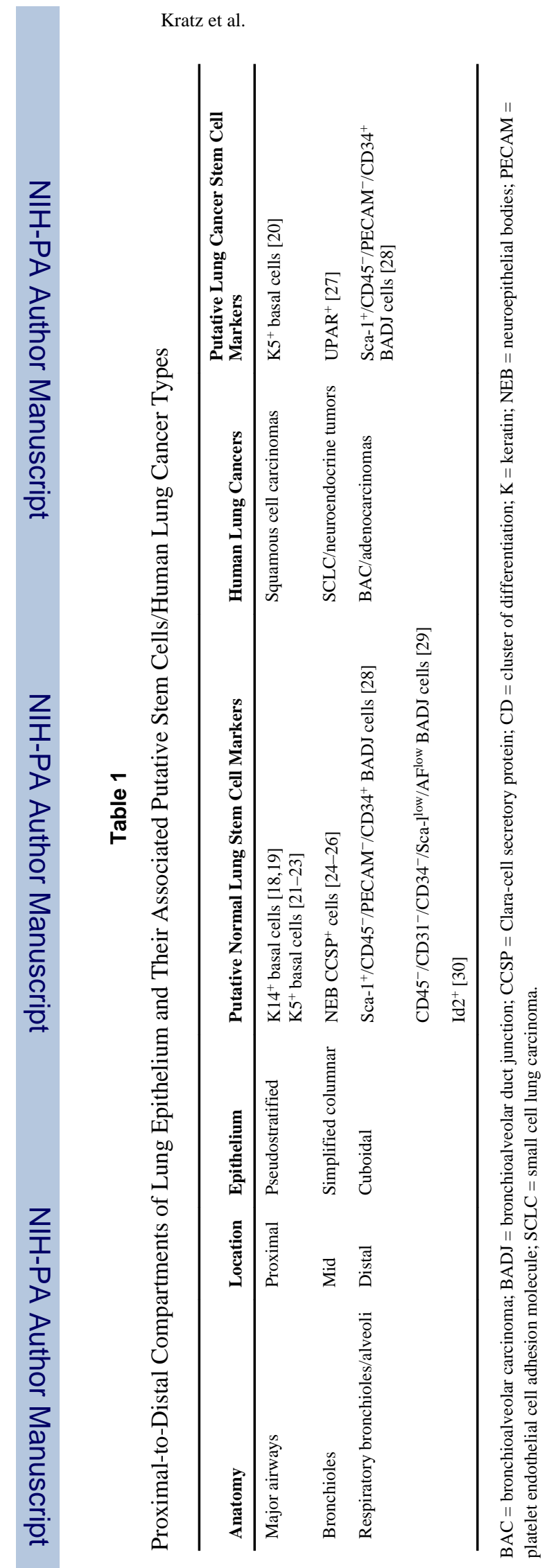

Page 11 